\title{
On the Application of APFIM to Investigation of Site Occupancy of Pt in $\beta$-NiAl
}

\author{
Krystyna Stiller*, Johan Angenete*
}

*Dept. of Experimental Physics, Chalmers University of Technology, 41296 Göteborg, Sweden

Ordered intermetallic $\beta$-NiAl alloys belong to an important group of advanced materials, used in high temperature applications. Due to their high Al content, the alloys provide good oxidation resistance and are therefore used as protective coatings on nickel base superalloys to minimise the environmental degradation due to high temperature oxidation.

Under the last decades, small additions of Pt to such coatings have been extensively used since this proves to have a beneficial effect on the time during which the coating is able to produce a protective layer of alumina $\left(\mathrm{Al}_{2} \mathrm{O}_{3}\right)$ [1,2]. Some of the proposed mechanisms behind this improvement of the oxidation properties of the coatings are based either on the influence of $\mathrm{Pt}$ on the diffusion behaviour of $\mathrm{Ni}$ and $\mathrm{Al}$ in the material or on its stabilisation of the $\beta$-NiAl phase [3-5]. At present, there is still no consensus in this matter, due to contradictory experimental results and the limited amount of thermodynamical and diffusion data for the NiAlPt system.

One of the possible ways of bringing more clarity in this issue is to investigate the site occupancy behaviour of $\mathrm{Pt}$ in $\beta$-NiAl. An uneven distribution of $\mathrm{Pt}$ on $\mathrm{Ni}$ or $\mathrm{Al}$ sites may explain its alleged influence on the diffusivity of $\mathrm{Ni}$ and $\mathrm{Al}$. The atom probe technique, with its high spatial resolution, is ideally suited for such investigations and it was therefore used to study the platinum site occupancy in a stoichiometric, polycrystalline $\beta$-NiAl alloy containing 1 at $\% \mathrm{Pt}$.

The APFIM specimens were prepared using the Focused Ion Beam method [6], to avoid thin oxide film on the tip produced by the standard electropolishing procedure. The analyses were performed along the $\langle 100\rangle$ direction of the specimen in order to resolve pure $\{001\} \mathrm{Ni}$ and $\mathrm{Al}$ planes (Fig. 1). The other possible direction for resolution of pure $\mathrm{Ni}$ and Al planes, <111>, was not used because of the observed retention of $\mathrm{Pt}$ on the $\{111\}$ planes.

Due to the difference in evaporation field of $\mathrm{Al}$ and $\mathrm{Ni}$, the reconstructed $\mathrm{Ni}$ planes appeared somewhat blurred while the Al planes were clearly visible. The Pt atoms were observed both in and between the Al planes (Fig. 2). This was interpreted as a sign for Pt location both on Ni and Al sites.

Calculation of the chemical environment around the $\mathrm{Pt}$ atoms (i.e. in slabs with thickness corresponding to a half a distance between the adjacent $\mathrm{Ni}$ or $\mathrm{Al}$ planes) indicated that $\mathrm{Pt}$ atoms were quite evenly distributed between $\mathrm{Al}$ and $\mathrm{Ni}$ sites.

A more detailed statistical method, termed stacked profile, by which it was possible to calculate the average chemical environment of all $\mathrm{Pt}$ atoms, was developed [7]. In these calculations, slabs with two lattice parameters width around each Pt atom were extracted from the original dataset. These subsets were put together in a new coordinate system, with the Pt atoms at the origin. This resulted in a very dense dataset, in which accurate chemical profiles (based 
on over 60,000 atoms $/ \AA$ ) could be determined. This closer look on the occurrence of Ni and Al atoms around the $\mathrm{Pt}$ atoms revealed a very slight preference for Pt to occupy Al sites (Fig. 3).

\section{References}

[1]. G Lehnert and H.W. Meinhardt, Electrodep. Surf. Treat., 189 (1972) 71

[2] P.S. Korinko et al., Proceed. International Gas Turbine and Aeroengine Congress and Exhibition, ASME, New York, NY, USA (1996) 1

[3] H. M. Tawancy et al., Surf. Coat. Technol., 39/49 (1991) 1

[4] H. M. Tawancy, et al., Scripta Met. Mat., 33 (1995) 1431

[5] C.Jia et al., Metall. Trans. A, 25 (1994) 473

[6] D.J. Larson et al., Ultramicroscopy, 79 (1999) 287

[7] J. Angenete et al., Mat. Sci. Eng. A, in press.

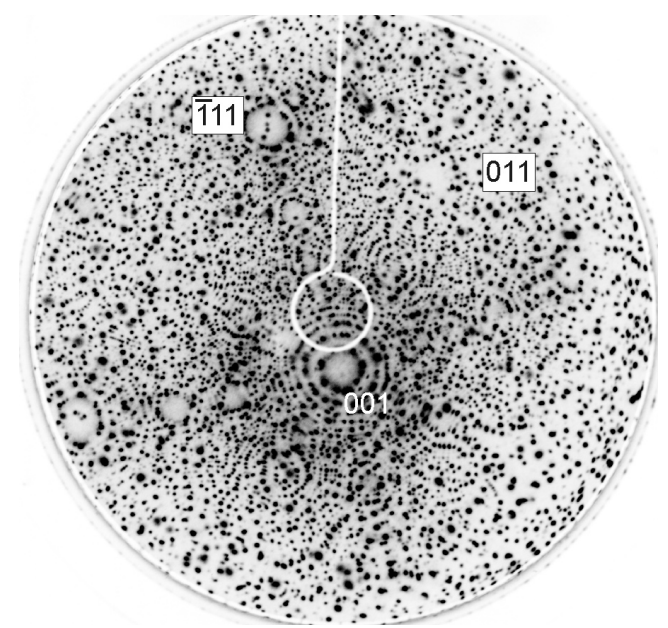

Fig. 1. Typical FIM image close to the $\{001\}$ pole. The image was acquired in $\mathrm{Ne}$ at about $20 \mathrm{~K}$ during DC evaporation at approximately $13 \mathrm{kV}$.

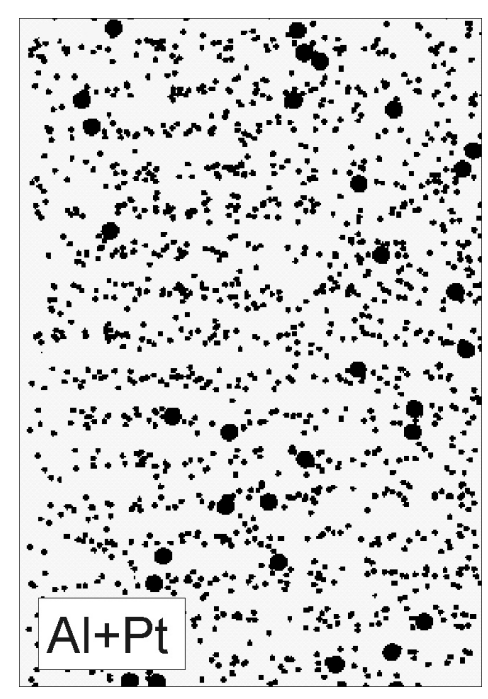

Fig. 2. Atom map, showing Al planes and Pt atoms (large black dots).

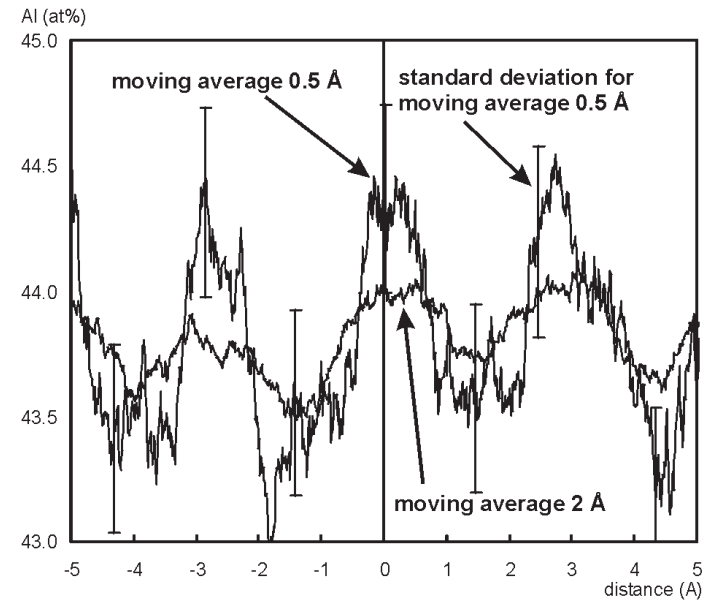

Fig. 3. Stacked profile over $797 \mathrm{Pt}$ atoms, placed at $\mathrm{z}=0$. The composition was calculated over two different moving averages, 0.5 and $2 \AA$ wide. The error limits are given by the standard deviation for the $0.5 \AA$ calculation. 